\title{
THE “ARMS RACE” ON AMERICAN ROADS: THE EFFECT OF HEAVY VEHICLES ON TRAFFIC SAFETY AND THE FAILURE OF LIABILITY RULES
}

\author{
Michelle J. White \\ Working Paper 9302 \\ http://www.nber.org/papers/w9302
NATIONAL BUREAU OF ECONOMIC RESEARCH 1050 Massachusetts Avenue Cambridge, MA 02138
October 2002

I am grateful to the Institute of Civil Justice at RAND for research support, to Orla Hayden for research assistance and to Roger Gordon, Valerie Ramey, Steve Carroll, and Bob Reville for helpful comments. The views expressed herein are those of the authors and not necessarily those of the National Bureau of Economic Research.

(C) 2002 by Michelle J. White. All rights reserved. Short sections of text, not to exceed two paragraphs, may be quoted without explicit permission provided that full credit, including (C) notice, is given to the source. 
The "Arms Race" on American Roads: The Effect of Heavy Vehicles on Traffic Safety and the Failure of Liability Rules

Michelle J. White

NBER Working Paper No. 9302

October 2002

JEL No. R4, K1

ABSTRACT

Drivers have been running an "arms race" on American roads by buying increasingly heavy vehicles such as SUVs, vans and light trucks. Families view large vehicles as providing better protection to their own occupants if a crash occurs, but these vehicles pose an increased danger to occupants of smaller vehicles and to pedestrians and bicyclists. This paper measures both the beneficial internal effect and the negative external effect of heavier vehicles. The main result is that when drivers replace cars with light trucks, 3,700 additional crashes per year involving fatalities of smaller vehicle occupants, pedestrians and bicyclists occur, while only 1,400 crashes involving fatalities of light truck occupants are avoided, i.e., the ratio of negative external effects to positive internal effects is $2 \frac{1}{2}$ to 1 . The paper argues that none of the existing traffic laws or institutions forces drivers of heavy vehicles to take account of their negative external effects.

Michelle J. White

Department of Economics

University of California, San Diego

9500 Gilman Dr.

La Jolla CA 92093-0508

and NBER

miwhite@ucsd.edu 


\section{The "Arms Race" on American Roads: The Effect of SUV's and Light Trucks on Traffic Safety ${ }^{1}$}

Michelle J. White

\section{Introduction}

Over the last decade, drivers have been running an "arms race" on American roads, replacing cars with sport utility vehicles (SUVs) and light trucks and then replacing these vehicles with even larger SUVs and even heavier trucks, including the tank-like Hummer. ${ }^{2}$ An important reason for the popularity of large vehicles is that families view them as providing better protection to their occupants if a crash occurs. But when families drive larger vehicles, they pose an increased danger to occupants of smaller vehicles and to pedestrians and bicyclists. In this paper, I measure both the beneficial internal effect of heavier vehicles on their own occupants when crashes occur and the negative external effect of heavier vehicles on occupants of lighter vehicles, pedestrians and bicyclists.

The effect of SUVs and light trucks on traffic safety is controversial. Several researchers have argued that increases in average vehicle weight are associated with reductions in fatalities, and vice versa. Based on this, they argue that governmentmandated increases in fuel economy standards in the 1970's, which led automakers to reduce vehicle weight, caused fatalities to rise. But studies by the National Highway Traffic Safety Administration (1991) and (1997) have shown that damage to occupants of cars in two vehicle crashes is higher when cars are involved in crashes with SUV's or light trucks than when they are involved in crashes with other cars. These divergent points of view reflect confusion about two distinct effects of vehicle weight/size on

\footnotetext{
${ }^{1}$ I am grateful to the Institute of Civil Justice at RAND for research support, to Orla Hayden for research assistance and to Roger Gordon, Valerie Ramey, Steve Carroll, and Bob Reville for helpful comments. ${ }^{2}$ Between 1980 and 1998, yearly production of light trucks (including SUV's and vans) more than tripled, from approximately 2 million to 7 million per year. The fraction of registered vehicles in the U.S. that consists of trucks increased over the same period from $21 \%$ to $37 \%$. (Note that part of the increase is due to the fact that SUV's and vans were re-classified from cars to trucks starting in 1985.) As of 1999, the number of registered SUVs and light trucks was 19 million and 55 million, respectively, compared to 132
} 
traffic safety. First, if larger, heavier vehicles protect their occupants better in crashes, then an increase in the weight of all vehicles would increase traffic safety. In other words, passengers would be safer in a fleet composed entirely of light trucks or entirely of SUV's than in one composed entirely of cars. Second, vehicle fleets are never homogeneous, particularly if pedestrians and bicyclists are considered to be ultra-light vehicles. If a vehicle fleet is initially composed entirely of cars, but some cars are replaced by SUVs or light trucks, then the probability of crashes involving different types of vehicles rises. In these heterogeneous crashes, occupants of smaller vehicles are more likely to be killed or injured than if the other vehicle were the same weight and occupants of larger vehicles are less likely to be killed or injured than if the other vehicle were the same weight. Overall, the effect on safety of an increase in average vehicle weight could either be positive or negative, depending on which of these two effects is more important.

As an example, suppose there are 1,000 vehicles in a town and each vehicle is either heavy or light. Also suppose all vehicles have a $2 \%$ probability of being involved in a crash each year and all crashes involve two vehicles, so there are 10 crashes per year. The cost per crash is assumed to be $\$ 10$ if two heavy vehicles are involved, $\$ 15$ if two light vehicles are involved, and \$25 if one heavy and one light vehicle are involved. If all vehicles are initially light, the total cost of accidents is $\$ 150$. As some vehicles shift from light to heavy, it rises to a maximum of $\$ 190$ when the proportion of heavy to light vehicles is $40 / 60$. Then as the fraction of heavy vehicles continues to rise, total accident costs gradually fall to $\$ 100$ when all vehicles are heavy. Thus the marginal effect of an increase in the proportion of heavy vehicles could be either an increase or a decrease in the total cost of crashes.

This study is the first to use micro data on traffic crashes to examine the effect of fleet composition on the cost of crashes. It divides the cost of accidents into internal benefits versus external costs. The internal benefits of larger vehicles are the greater safety they provide to their own occupants in both two-vehicle and single-vehicle crashes. The external costs of larger vehicles are their negative effects on the safety of occupants of lighter vehicles, pedestrians, and bicyclists. The main result of the paper is that when

million registered cars. Data are taken from the Statistical Abstract of the U.S. (2000), tables 1027 and 1030, and Federal Highway Administration, Highway Statistics. 
drivers replace cars with light trucks, each crash involving fatalities of light truck occupants that is prevented comes at a cost of $2 \frac{1}{2}$ additional crashes involving fatalities of car occupants, pedestrians or bicyclists. Thus the beneficial internal effect of light trucks is much smaller than their adverse external effect.

Section II reviews the literature and sections III-V describe the data and specification, and present the results. Section VI examines why liability rules and other legal institutions fail to internalize the negative external effects of heavy vehicles.

\section{Literature Review}

Meyer and Gomez-Ibanez (1981, p. 264) were the first to consider the effect of vehicle heterogeneity on safety. They present a table showing the average probability of vehicle occupants suffering serious injury if their vehicle is in any of five size classes and has a crashes with another vehicle in any size class. Their data show that occupants of the smallest vehicles are $58 \%$ more likely to be injured when they have a crash with another vehicle in the largest rather than the smallest size class. Conversely occupants of the largest vehicles are $61 \%$ less likely to be injured when they have a crash with a vehicle in the smallest rather than the largest size class.

More recently, Crandall and Graham (1989) used aggregate U.S. data for the 1970's and 1980's to analyze the effect of Federal government standards requiring improved fuel economy (CAFÉ standards). They argued that the CAFÉ standards were responsible for $2,200-3,900$ additional deaths and 11,000 - 19,500 additional serious injuries over a ten-year period, because automakers responded to the standards by reducing vehicle weight. More recently, Keeler (1996) used county level data for 1980 and 1990 to explain traffic fatalities. While the goal of his study was to examine whether regulatory policies such as mandated safety devices and speed limits affect traffic safety, he also included as control variables measures of the proportion of vehicles that were light and heavy trucks. These variables were not statistically significant. Coate and VanderHoff (2001) used state level data for several years in the 1990's to examine whether the increase in the proportion of U.S. vehicles that consist of SUV's and light trucks in the U.S. has reduced traffic fatalities. They argued that additional SUV's and light trucks reduced fatalities. 
Because the Crandall-Graham, Keeler, and Coate-VanderHoff studies all used aggregate data over multiple year periods, they encounter the difficulty that changes in mandated safety equipment and practices, such as seatbelts, anti-lock brakes, airbags, strengthened door panels, and laws requiring use of seat belts, occurred over the same period. These changes tend to reduce the number of fatal crashes, ${ }^{3}$ so that a study like Coate and VanderHoff could be attributing the reduction in fatalities to the rise in the number of SUV's and light trucks when it is actually due to improvements in mandated safety equipment or use of seatbelts. Using micro data on crashes rather than aggregate data makes it possible to separate out these effects.

\section{Data}

The dataset is a sample of police-reported motor vehicle crashes produced by the National Highway Traffic Safety Administration General Estimates System (available at http://www-nass.nhtsa.dot.gov/nass/). The information includes the vehicle types of all vehicles involved in a crash, the circumstances of the crash, and information concerning injuries to occupants of all vehicles involved and to pedestrians or bicyclists. I examine three types of crashes: those involving two vehicles, those involving a single vehicle, and those involving a vehicle striking a pedestrian or cyclist. ${ }^{4}$ Vehicles are divided into five categories: cars, SUV's, small trucks (including pickup trucks and vans), large trucks, and buses. ${ }^{5}$ Five separate datasets are analyzed. They consist of all two-vehicle crashes involving one or two cars, all two-vehicle crashes involving one or two SUVs, all twovehicle crashes involving one or two light trucks, all crashes involving single vehicles, and all crashes involving a vehicle and a pedestrian or bicyclist. All datasets cover the period 1995-99.

Using crash data has the advantage of providing detailed information on the circumstances of each crash. But a drawback is that they do not allow the researcher to

\footnotetext{
${ }^{3}$ Although Peltzman (1975) argued that drivers compensate for safety increase due to seatbelts by driving faster.

${ }^{4}$ Two other types of crashes are omitted: those involving more than two vehicles ( $7.9 \%$ of crashes) and those involving motorcycles ( $1 \%$ of crashes). Estimates of the total number of crashes adjust for these omitted types.

${ }^{5}$ The heavy truck category includes all "single unit straight trucks," combination trucks, and medium or heavy motorhomes. Van-based schoolbuses are classified as buses, but all other types of vans are classified as light trucks, regardless of whether they are used for commercial or personal transportation purposes.
} 
take account of differences in the probability of particular types of vehicles being involved in crashes. Unfortunately, there is little micro data available on whether household involvement in crashes. See section $\mathrm{V}$ below for discussion of aggregate crash probabilities by type of vehicle.

\section{Specification and Results}

The basic specification is a set of logit regressions explaining whether occupants of particular types of vehicles are killed or seriously injured when their vehicles are involved in crashes with larger versus smaller vehicles. I discuss the specification and results for each of the five datasets separately below.

A. Injuries and fatalities in two vehicle crashes involving cars. The first dataset consists of all two-vehicle crashes that involve at least one car. Define "vehicle one" (V1) to be the car and "vehicle two" (V2) to be the other vehicle. If both vehicles are cars, then one car is chosen randomly to be vehicle one. ${ }^{6}$ The dependent variables are a dummy variable which equals one if one or more occupants of vehicle one were killed in the crash and a dummy which equals one if one or more occupants of vehicle one were seriously injured (but not killed) in the crash. There are about 136,000 two-vehicle crashes involving cars.

The most important independent variables are separate dummy variables for whether vehicle two is an SUV, a light truck, a heavy truck, or a bus. The omitted category is another car. The coefficients of these dummy variables measure the change in the probability of vehicle one occupants suffering fatalities or serious injuries when vehicle two is an SUV rather than another car, a light truck rather than another car, etc. The hypothesis is that, conditional on a crash occurring, occupants of cars are more likely to be injured or killed if the other vehicle involved in the crash is a heavier vehicle rather than another car. All of the dummy variables are predicted to have positive signs.

I also include a set of exogenous variables intended to control for circumstances of the crash that affect whether fatalities or serious injuries occur. These include dummy

\footnotetext{
${ }^{6}$ Ideally, vehicle one would be the lightest of the two cars, but the dataset does not contain information on vehicle weight.
} 
variables for whether the crash occurred in rain, snow, or fog (the omitted category is clear weather), whether the crash occurred in darkness, whether the crash occurred in a medium or large city (the omitted category is a small town or rural area), whether the crash occurred on an interstate highway or a divided highway (the omitted category is a two-way street), and whether the crash occurred on a weekday. I also include separate dummy variables for whether the driver of vehicle one or vehicle two was driving more than ten miles per hour above the speed limit, separate dummy variables for whether the driver of vehicle one or vehicle two or both were driving negligently (this includes driving when drunk or under the influence of drugs), separate variables for whether the driver of vehicle one was under 21 or over 60 years of age and the same for the driver of vehicle two, the number of occupants in vehicle one when the crash occurred and the same for vehicle two, and whether the driver of vehicle one wore a seatbelt. Year dummy variables are included to account for changes in mandated safety standards and seatbelt use over the period of the sample (results for the latter are not shown). Weights are used to make the sample representative of all accidents. ${ }^{7}$

Summary statistics are shown in table 1, column 3 . The results of logit regressions explaining whether there were fatalities or serious injuries of occupants of vehicle one when two-vehicle crashes occurred are shown in table 1, columns 1 and 2, respectively. Standard errors are shown in parentheses. All of the dummy variables for heavier vehicles than cars have the predicted positive signs and all are statistically significant, except that the V2 = SUV dummy in the fatalities regression and the V2 = bus dummy in the serious injuries regression are not significant. Among the other variables, occupants of vehicle one are more likely to be killed or seriously injured in crashes that occur in rural areas rather than cities, in crashes that occur on weekends rather than weekdays, in crashes in which either vehicle's speed was more than 10 miles per hour above the limit, in crashes in which the driver of vehicle one was more than 60 years old, and when vehicle one contained more occupants. Occupants of vehicle one are less likely to be killed or seriously injured if the driver wore a seatbelt and more likely to be killed or

\footnotetext{
${ }^{7}$ The dataset does not include the state in which the accident occurred, so that state dummy variables cannot be used. But the weights are designed to take care of the problem that different states' reporting systems include varying proportions of accidents of particular types.
} 
seriously injured if both drivers drove negligently. But, surprisingly, if one rather than both drivers drove negligently, the sign pattern is mixed.

Table 2, top panel, shows how the number of two-vehicle crashes per year involving fatalities or serious injuries of car occupants would change if cars replaced each of the various types of heavier vehicles. ${ }^{8}$ If cars replaced all SUV's on the roads, there would be 202 fewer crashes per year involving deaths of car occupants and 1,008 fewer crashes per year involving serious injuries of car occupants. This is because cars would be less likely to be involved in two-vehicle crashes with heavier vehicles and more likely to be involved in crashes with other cars. If cars replaced all light trucks on the road, there would be 1,445 fewer crashes per year involving deaths and 11,325 fewer crashes per year involving serious injuries of car occupants. If cars replaced all heavy trucks on the road, there would be 561 fewer crashes per year involving fatalities of car occupants and 3,384 fewer crashes per year involving serious injuries of car occupants. Overall if cars replaced all heavier vehicles, there would be about 2,250 fewer crashes involving deaths of car occupants and 15,000 fewer crashes involving serious injuries of car occupants each year. These results suggest that the negative external effect of heavier vehicles on cars is substantial.

B. Injuries and fatalities in two vehicle crashes involving SUVs. The next dataset consists of all two-vehicle crashes involving at least one SUV. Define "vehicle one" to be the SUV and "vehicle two" to be the other vehicle. If both vehicles are SUVs, then one SUV is randomly chosen to be vehicle one. The dependent variables are dummies that equal one if one or more fatalities occurred in vehicle one and if one or more serious injuries occurred in vehicle one. The key independent variables are dummy variables for whether vehicle two is a car, a light truck, a heavy truck, or a bus (the omitted category is

\footnotetext{
${ }^{8}$ These calculations first transform the logit coefficients into average marginal effects using the weighted average probability of fatalities when two-vehicle crashes involving cars occur. To convert the marginal effect into a prediction of the change in the number of crashes involving fatalities if cars were substituted for all SUVs on U.S. roads, the average marginal effect is multiplied by the total number of crashes per year in the U.S. times the proportion of all crashes involving two vehicles times the proportion of two vehicle crashes involving a car and an SUV. The average number of crashes per year during the period of the data was 6,500,000 (taken from Traffic Safety Facts, available at www.nhtsa.dot.gov). The other figures are calculated from the datasets and given in the Appendix. Calculations for other types of vehicles and for crashes involving serious injuries use analogous procedures. Note that the calculations use the estimated coefficients from table 2 even if they are not statistically significant, since the coefficients represent the most likely value.
} 
another SUV). The predicted sign of the $\mathrm{V} 2=$ car variable is negative, since we predict that occupants of SUVs are less likely to be killed or injured in two-vehicle crashes if the other vehicle is a car rather than another SUV (i.e., a lighter vehicle). The predicted signs of the V2 = light truck, V2 = heavy truck, and V2 = bus variables are positive, since we predict that occupants of SUVs are more likely to be kllled or injured in crashes if the other vehicle is heavier than an SUV. The control variables are the same as in the previous regressions. There are about 15,300 two vehicle crashes involving SUVs.

Summary statistics are shown in table 3, column 3 . Table 3, columns 1 and 2 give the results of the logit regressions. As predicted, the coefficients of the $\mathrm{V} 2=$ car variable are negative in both regressions, while the coefficients of the $\mathrm{V} 2=$ light truck and $\mathrm{V} 2=$ heavy truck variables are positive in both regressions. Thus SUV occupants are less likely to be killed or seriously injured when their vehicles are involved in crashes with cars and more likely to be killed or seriously injured when their vehicles are involved in crashes with light or heavy trucks. However, only the heavy truck dummy variable in the regression explaining serious injuries is statistically significant, because of the small number of crashes involving fatalities or serious injuries. ${ }^{9}$ The results for other variables are similar to those in the car dataset.

Table 2, second panel, shows the predicted change in the number of two-vehicle crashes involving fatalities and serious injuries of SUV occupants per year if other types of vehicles were replaced by SUVs. If all cars were replaced by SUVs, there would be 349 additional crashes per year in which occupants of SUVs are killed and 927 additional crashes in which occupants of SUVs are seriously injured. This is because SUV occupants would no longer gain from having some crashes with lighter vehicles. If all light or heavy trucks were replaced by SUVs, there would be 25 and 13 fewer crashes per year, respectively, in which occupants of SUVs are killed and 347 and 184 fewer crashes per year, respectively, in which occupants of SUV's are seriously injured. Thus, while trucks impose large negative externalities on occupants of cars, they impose only small negative externalities on occupants of SUVs.

\footnotetext{
${ }^{9}$ There are only 16 fatal crashes and 235 crashes involving serious injuries in the SUV sample. The V2 = bus variable in the regression explaining serious injuries has the wrong sign, but is not significant.
} 
C. Injuries and fatalities in two vehicle crashes involving light trucks. The next dataset consists of all two-vehicle crashes involving one or more light trucks. Define "vehicle one" to be the light truck and "vehicle two" to be the other vehicle. If both vehicles involved in the crash are light trucks, then one is randomly chosen to be vehicle one. The dependent variables are dummies that equal one if one or more fatalities occurred in vehicle one and if one or more serious injuries occurred in vehicle one. The key independent variables are separate dummy variables for whether vehicle two is a car, an SUV, a heavy truck, or a bus (the omitted category is another light truck). The predicted signs of the V2 = car and V2 $=$ SUV variables are negative, since occupants of light trucks are less likely to be killed or injured in two-vehicle crashes if the other vehicle involved in the crash is lighter than a light truck. The predicted signs of the V2 = heavy truck and $\mathrm{V} 2$ = bus variables are positive, since occupants of light trucks are more likely to be kllled or injured in crashes if the other vehicle is heavier than a light truck. The control variables are the same as in the previous regressions. There are about 56,000 two-vehicle crashes involving light trucks.

Summary statistics are shown in table 4, column 3. Table 4, columns 1 and 2, give the results. In both regressions, the coefficients of the V2 $=$ car and V2 $=$ SUV dummy variables are negative as predicted and the coefficients of the $\mathrm{V} 2=$ heavy truck and $\mathrm{V} 2=$ bus dummy variables are positive as predicted. The V2 $=$ car and V2 = heavy truck variables are statistically significant in both regressions, but the V2 $=\mathrm{SUV}$ and V2 $=$ bus dummy variables are not.

Table 2, third panel, shows the predicted change in the number of crashes involving fatalities and serious injuries of light truck occupants if other types of vehicles were replaced by light trucks. If light trucks replaced all cars on the road, there would be 864 additional crashes per year involving fatalities of light truck occupants and 8,000 additional crashes per year involving serious injuries of light truck occupants. This is because light truck occupants would lose some of the protective effect of frequently having crashes with lighter vehicles. If light trucks replaced all SUV's on the road, there would be little effect on occupants of light trucks. If light trucks replaced all heavy trucks on the road, there would be 95 fewer crashes per year involving fatalities of light truck occupants and 722 fewer crashes per year involving serious injuries of light truck 
occupants. This is because light truck occupants would gain from having fewer crashes with heavier vehicles.

D. Injuries and fatalities in single vehicle crashes. The next dataset consists of all single vehicle crashes. These crashes are more heterogeneous than those in the previous datasets, since crashes may involve vehicles striking trees, highway barriers or road signs, leaving the road, and/or rolling over. The dependent variables are dummy variables that equal one if one or more occupants of the vehicle involved in the crash were killed or seriously injured. The key independent variables are separate dummy variables for whether the vehicle is an SUV, a light truck, a heavy truck, or a bus (the omitted category is a car). Because of the heterogeneity of single vehicle crashes, we do not have a hypothesis concerning the predicted signs of these variables-i.e., heavier vehicles may protect their occupants better or worse than light vehicles in crashes. The control variables are similar to those in the previous regressions. There are about 12,000 single vehicle crashes in the dataset.

Table 5, columns 1 and 2, give the results of logit regressions explaining fatalities and serious injuries in single vehicle crashes and column 3 gives summary statistics. ${ }^{10}$ All four dummy variables for vehicle types have positive signs in the regression explaining fatalities, but only SUV and bus variables are statistically significant. In the serious injury regression, the light truck dummy variable has a negative sign and is statistically significant, while the heavy truck dummy has a positive sign. Coefficients could not be computed for the SUV and bus dummy variables. Thus in single vehicle crashes, occupants of heavier vehicles are more likely to be killed than occupants of cars, but may be better protected against serious injuries than occupants of cars.

Table 2, fourth panel, shows the predicted change in the number of single vehicle crashes involving fatalities or injuries if cars replaced heavier vehicles. If SUVs replaced all cars on the road, there would be 27 fewer single vehicle crashes per year involving fatalities. If light trucks replaced all cars, there would be 58 fewer single vehicle crashes per year involving fatalities, but 485 additional single-vehicle crashes involving serious injuries. If heavy trucks or buses replaced all cars on the road, the 
effects on the number of single vehicle crashes involving fatalities and serious injuries would be small.

E. Injuries and fatalities in crashes involving pedestrians or cyclists. The final dataset consists of crashes involving a vehicle and a pedestrian or cyclist. The dependent variables are dummies for whether the pedestrian or cyclist was killed or seriously injured in the crash. The key independent variables are separate dummy variables for whether the vehicle was an SUV, a light truck, a heavy truck, or a bus. The omitted category is a car. The hypothesis is that pedestrians and cyclists are more likely to be killed or seriously injured when they are struck by heavier vehicles rather than cars. The control variables are similar to those in the previous regressions. There were about 14,000 crashes involving pedestrians or cyclists.

The results of the logit regressions are given in table 6, columns 1 and 2, and summary statistics are given in column 3. All of the dummy variables for vehicle type have positive signs in the regression explaining fatalities and the light truck and heavy truck variables are statistically significant. In the regression explaining serious injuries, the light truck and heavy truck variables both have the predicted positive signs and are statistically significant, but the SUV and bus dummy variables are both negative and insignificant. Among the control variables, fatalities and serious injuries are less likely to occur in large cities, more likely to occur in the dark, more likely to occur on divided or interstate highways, and more likely to occur if the driver of the vehicle was driving more than 10 miles per hour above the speed limit. Pedestrians and cyclists are also more likely to be killed or injured if they are more than 60 years old and less likely to be injured or killed if they are less than 21 years old. ${ }^{11}$

Table 2, bottom panel, gives the predicted changes in the number of crashes involving fatalities and serious injuries of pedestrians or cyclists if cars replaced heavier vehicles. If cars replaced all SUVs, then 594 fewer crashes involving deaths of pedestrians/cyclists would occur each year, but 673 additional crashes involving serious injuries of pedestrians/cyclists would occur. (Note that the latter figure is not significantly different

\footnotetext{
${ }^{10}$ Again the number of crashes involving fatalities and serious injuries is relatively small—only 10 and 77 , respectively. A dummy variable for crashes involving rollovers was tried, but no coefficient could be computed because there were only six rollover crashes in the data.
} 
from zero.) If cars replaced all light trucks, then 2,225 fewer crashes involving deaths and 4,633 fewer crashes involving serious injuries of pedestrians/cyclists would occur. If cars replaced all heavy trucks, then 486 fewer crashes involving deaths and 777 fewer crashes involving serious injuries of pedestrians/cyclists would occur. Thus if cars replaced all SUVs and light trucks, at least 3,300 lives of pedestrian or cyclist would be saved each year. Since the total number of pedestrian/cyclist fatalities in motor vehicle crashes in the U.S. is about 6,000 per year, this implies that light trucks and SUVs are responsible for more than half of all deaths of pedestrian/bicyclists.

\section{External versus Internal Effects of Large Vehicles}

Now turn to the external versus internal effects of large vehicles. Consider two separate experiments - replacing all SUVs in the existing U.S. vehicle fleet with an equal number of cars or replacing all light trucks with an equal number of cars. I focus on SUVs and light trucks since virtually all SUVs and many light trucks are used for nonbusiness purposes and therefore could be replaced by cars with little loss of efficiency.

Table 7 shows the results for fatalities. Each external and internal effect is shown in a separate row and the results for replacing SUVs or light trucks with cars are shown in separate columns. The first three rows are all external effects, of which the first is the reduction in the number of two-vehicle crashes involving fatalities of car occupants when all SUVs or all light trucks are replaced by cars. If all SUVs or all light trucks were replaced by cars, there would be 202 and 1,445 fewer crashes per year involving fatalities, respectively. ${ }^{12}$ The second row is the reduction in the number of two-vehicle crashes involving fatalities of SUV occupants when all light trucks are replaced by carsthis figure is 25 per year. (Note that this external effect does not apply when SUVs are replaced by cars.) The final external effect, in the third row, is the reduction in the number of crashes involving fatalities of pedestrians/bicyclists if all SUVs or all light trucks were replaced by cars. These figures are 594 and 2,225, respectively. Combining all three external effects, we find that the total number of fatal crashes per year involving

\footnotetext{
${ }^{11}$ The results remained virtually the same if a dummy variable for the victim being a cyclist versus a pedestrian was included.
} 
lighter vehicles, pedestrians or bicyclists that would be avoided if cars replaced all SUVs is 796 and the figure for light trucks is 3,695.

Now turn to the internal effects of replacing SUVs or light trucks with cars. The first internal effect is the reduction in the number of single vehicle crashes involving fatalities that would occur each year if all SUVs or all light trucks were replaced by cars. These figures are 27 and 58, respectively. The last internal effect is the increase in the number of two-vehicle crashes involving fatalities of SUV and light truck occupants that would occur if occupants of these vehicles instead used cars and therefore lost the protective effect of their large vehicles.

To calculate this effect for SUV occupants, we first use the results of the SUV logit model reported in table 3 , column 1 , to predict the weighted average probability of crashes involving fatalities of SUV occupants when they are in two-vehicle crashes with the existing distribution of vehicle types. ${ }^{13}$ This figure is .00111 . We then use the results of the car logit model reported in table 1 , column 1 , to predict the weighted average probability of crashes involving fatalities occurring when erstwhile SUV occupants shift to driving cars. But instead of evaluating the car logit at the actual distribution of vehicle types, we use the distribution of vehicle types that would occur if all SUVs were replaced by cars, i.e., we set the V2 $=$ SUV dummy variable to zero. The resulting probability is .00156 . This means when SUV occupants shift to cars, their probability of fatalities conditional on a two-vehicle crash occurring rises by .00156 $.00111=.00044$. Since the total number of crashes per year involving SUVs is $4,167,000$, replacing all SUVs with cars raises the number of fatal crashes that erstwhile SUV occupants experience each year by $(.00044)(4,167,000)=1,846$. The analogous calculation for replacing all light trucks with cars results in a prediction that erstwhile light truck occupants will experience $(.00130-.000969)(4,542,000)=1,493$ additional crashes involving fatalities per year. Combining the two internal effects, we find that if cars replaced all SUVs, there would be 1,819 additional fatal crashes per year involving

\footnotetext{
${ }^{12}$ All of the figures in table 7 are taken from table 2, except for the last internal effect (see the discussion below). The signs are reversed from those in table 2 because the conceptual experiment involves replacing heavier vehicles with cars rather than the opposite.

${ }^{13}$ This figure is calculated by first predicting the probability of a crash involving fatalities occurring for each observation in the SUV dataset and then taking a weighted average. This procedure is followed for all of the models.
} 
erstwhile SUV occupants. The analogous figure for light trucks occupants is 1,435 . These figures are shown in table 7.

Combining the external and internal effects shows that the overall picture is quite different for SUVs versus light trucks. For light trucks, the positive external effect of 3,695 fatal crashes avoided when cars are substituted for light trucks is much greater than the internal cost of 1,435 additional fatal crashes involving erstwhile light truck occupants. This means that the ratio of external gain to internal harm is 2.6--for each additional fatal crash involving erstwhile occupants of light trucks, 2.6 fatal crashes involving occupants of smaller vehicles, bicyclists or pedestrians are avoided. In contrast for SUVs, the positive external effect of 796 fatal crashes avoided when cars are substituted for SUVs is smaller than the negative internal effect of 1,819 additional fatal crashes involving erstwhile SUV occupants, so that the ratio of external gain to internal harm is 0.44 . Thus for each additional fatal crash involving erstwhile occupants of SUVs, 0.44 fatal crashes involving occupants of cars, pedestrians or bicyclists are avoided.

Table 8 repeats the analysis for crashes involving severe injuries. The largest of the external or internal effects is the increase in the number of crashes involving serious injuries of erstwhile SUV or light truck occupants when they shift to driving cars. For SUV occupants, the average probability that a crash involves serious injuries is .0158 , but it rises to .0252 when SUV occupants instead drive cars. This implies that the increase in the number of crashes involving serious injuries is $(.0252-.0158) * 4,167,000=39,482$. For light truck occupants, the average probability that a crash involves serious injuries is .0173, compared to .0226 when light truck occupants instead drive cars, so that the predicted increase in the number of crashes involving serious injuries is (.0226 $.0173) * 4,542,000=24,284$. The resulting ratios of external to internal effects are .0008 for SUVs and .66 for light trucks. Thus while heavier vehicles impose external costs on occupants of smaller vehicles, pedestrians and bicyclists in terms of additional crashes involving serious injuries, these costs are lower than the number of serious injury crashes avoided for their own occupants.

Would these results change if differences in crash rates across types of vehicles were incorporated into the analysis? Aggregate data suggests that SUVs and light trucks have 
higher crash rates than cars: the figures are .034 per year for cars versus .04 for SUVs and light trucks. ${ }^{14}$ However a problem with aggregate crash data is that they do not address the question of whether and how crash rates would change if drivers shifted from one vehicle type to another. It seems likely that basic driving behavior would remain the same if drivers shifted from cars to SUVs or light trucks, i.e., safe drivers would continue to drive safely and reckless drivers would continue to drive recklessly. But drivers in general may tend to drive faster in SUVs or light trucks than in cars. This is because SUVs and light trucks are higher above the ground than cars and drivers perceive a given speed to be lower when they are seated higher off the ground. (At the extreme, passengers in an airplane perceive their speed as near zero. See Rist, 2001.) These considerations suggest that the external gains from replacing SUVs or light trucks with cars may be even larger than those calculated here and the internal costs even smaller.

\section{The Failure of Liability Rules}

This paper shows that families' decisions to drive heavy vehicles have large negative external effects. This section considers whether any of the existing legal institutionsincluding tort liability, traffic rules, and requirements that vehicle owners purchase liability insurance--internalize these negative effects.

Consider tort liability rules first. Tort liability makes injurers liable for victims' damage under certain circumstances and therefore gives drivers an incentive to use care to reduce the probability and severity of crashes (for background, see Shavell, 1987, and White, 1998). In theory, liability for damage should fall more heavily on owners of heavy than light vehicles and this should both cause drivers of heavy vehicles to use additional care to avoid accidents and discourage them from driving heavy vehicles in the

\footnotetext{
14 These figures are the number of police-reported crashes per year by type of vehicle divided by the number of registered vehicles of that type, averaged over 1995-99 (the period of our crash dataset). The number of crashes for each type of vehicle is calculated using figures from the crash dataset on the breakdown of crashes by type of vehicle (see the figures given in the Appendix) times 6,500,000 crashes per year, which is the average yearly number of police-reported motor vehicle crashes during 1995-99. The resulting figures for the number of crashes per year involving cars, SUVs, and light trucks are 4,425,000, 580,000 , and 2,092,000, respectively. The average number of registered vehicles is $130,000,000$, 14,700,000, and 52,800,000, respectively. Registration data are taken from Federal Highway Administration, Highway Statistics, available at www.fhwa.dot.gov. Data on total number of crashes by year are taken from National Highway Traffic Safety Administration, Traffic Safety Facts, wwwnrd.nhtsa.dot.gov.
} 
first place. However in practice, tort liability creates only weak incentive effects. One problem is that liability for damage in the traffic context is generally based on negligence, so that drivers are only liable if their care level falls below a standard. It is straightforward to show that if heavy vehicles cause higher damage than light vehicles at any given level of care, then the negligence standard for drivers of heavy vehicles should be set at a higher level than the standard for drivers of light vehicles; in other words, drivers of heavy vehicles should be required to drive more safely in order to avoid liability than drivers is light vehicles. A related problem is that negligence rules encourage a higher-than-optimal level of driving activity, because drivers escape liability for damage in crashes as long as their driving behavior is exceeds the negligence standard. Drivers therefore have an incentive to shift from light to heavy vehicles because they do not bear the cost of the additional crashes they cause, as long as their driving meets the standard. Both of these problems could be solved by imposing a higher negligence standard on drivers of heavy vehicles, such as by requiring them to drive at 10 miles per hour below the speed limit in order to avoid being found negligent, while drivers of light vehicles would only have to drive at the speed limit to avoid being found negligent. But the tort system in fact applies the same standard of care to drivers regardless of vehicle type.

Another problem with the tort liability system is that many states in the U.S. use nofault systems, rather than negligence rules, to determine liability in motor vehicle crashes. ${ }^{15}$ In states with no-fault, the liability system does not penalize drivers of heavy vehicles at all for causing more damage. In fact, drivers of light vehicles are at a disadvantage under no-fault, since they suffer more damage in crashes and pay these costs themselves.

Now consider traffic rules, which impose monetary fines, required attendance at traffic school, license suspension or other penalties on drivers who violate the rules. Traffic rules suffer from the same shortcoming as liability rules, since they apply the same standard of driving behavior and impose the same penalties on all drivers, regardless of vehicle type. They therefore do not discourage use of heavy vehicles. 
Finally consider liability insurance. Most states require vehicle owners to purchase liability insurance, so that the insurer rather than the driver pays compensation for damage to victims in crashes when the insured driver is liable. Because many drivers are judgment-proof, requiring that drivers purchase liability insurance increases the probability that crash victims will actually be able to collect when they legally entitled to do so. Also, insured drivers have an incentive to take care in driving even though their insurance companies pay damages, because insurance companies charge higher premiums when their expected liability is higher. These factors suggest that owners of heavy vehicles should pay higher insurance premiums, both because they are more likely to be involved in crashes and because their vehicles do more damage when crashes occur. But again the reality is different. Because the negligence and no-fault liability systems often allow drivers to escape liability for damage they cause, insurance of heavy vehicles do not necessarily pay higher insurance premiums. Another factor that affects insurance rates is that most states require drivers to purchase only a low level of liability coverage. Five states do not require drivers to purchase liability insurance at all, one state requires drivers to purchase only $\$ 10,000$ of coverage, and the most common minimum coverage requirement is only $\$ 25,000 .{ }^{16}$ Since damages in a crash involving a fatalities or serious injuries can be far higher, this means that drivers rarely pay for all of the damage their vehicles cause in serious crashes. Limited coverage requirements reduce insurance companies' incentive to set higher premiums for heavier vehicles, because the higher damage that these vehicles cause often exceeds the coverage limit. Another problem is that up to 30 percent of drivers in some states are uninsured. When drivers purchase liability insurance, they typically buy additional coverage for their own injuries if they are involved in a crash with an uninsured driver. The cost of uninsured drivers' coverage

\footnotetext{
${ }^{15}$ As of 1995, fifteen states in the U.S. used some version of no-fault, although some of them use a mixture of negligence and no-fault rules. See Liao and White (2002) for an analysis of no-fault liability rules in the motor vehicle accident context.

${ }^{16}$ The states that do not require owners of vehicles to purchase liability insurance are NH, TN, SC, VA and WI. The dollar figures are the required amount of insurance coverage for bodily injury to a single person injured in a crash (higher limits apply to all of the victims of a single crash). These figures are taken from www.insure.com/auto/minimum.html.
} 
is higher for drivers of light vehicles than heavy vehicles and it therefore raises the relative cost of liability insurance for light vehicles. ${ }^{17}$

These considerations suggest that the negative external effects of heavy vehicles are not internalized by liability rules, traffic rules or liability insurance. Obvious reforms would include requiring that vehicle owners in all states buy liability insurance and enforcing the requirement, raising minimum required levels of liability coverage, and replacing no-fault with fault-based liability systems for motor vehicle accidents. In addition, more stringent driving rules and negligence standards could be imposed on heavy vehicles - such as slower speed limits than those imposed on vehicles generally.

\footnotetext{
${ }^{17}$ According to a recent article by Consumer Reports magazine, insurance companies follow widely differing practices concerning pricing of liability insurance by type of vehicle. State Farm charges the same price for liability insurance regardless of vehicle type. In Missouri, GE Auto Insurance charges owners of pickups and SUVs lower liability premiums than it charges owners of cars. The article notes that GE Auto Insurance is in the process of extending this type of pricing to other states. Other insurance companies charge owners of SUVs and pickups more for liability insurance. See "Car Insurance for Less," Consumer Reports, vol. 67:10, October 2002, pp. 19-24.
} 
Table 1: Results of Logit Regressions Explaining Fatalities and Serious Injuries to Occupants of Cars Involved in Two Vehicle Crashes

\begin{tabular}{|c|c|c|c|}
\hline & Fatalities & Serious injuries & Summary statistics \\
\hline $\mathrm{V} 2=\mathrm{SUV}$ & $0.368(0.232)$ & $0.118(0.0604)$ & $.0869(.281)$ \\
\hline $\mathrm{V} 2=$ light truck & $0.669(0.150)$ & $0.338(0.0347)$ & $.340(.473)$ \\
\hline $\mathrm{V} 2=$ heavy truck & $1.85(0.161)$ & $0.719(0.0543)$ & $.0479(.213)$ \\
\hline $\mathrm{V} 2=\mathrm{bus}$ & $0.963(0.537)$ & $0.224(0.200)$ & $.0083(.0909)$ \\
\hline Medium city & $-0.870(0.242)$ & $-0.0452(0.0460)$ & $.124(.330)$ \\
\hline Large city & $-0.874(0.149)$ & $-0.653(0.0383)$ & $.309(.462)$ \\
\hline Used seatbelt (v1) & $-1.02(0.118)$ & $-0.565(0.129)$ & $.716(.451)$ \\
\hline Rain & $0.0937(0.173)$ & $-0.0653(.0499)$ & $.124(.329)$ \\
\hline Snow & $-0.522(0.426)$ & $-0.564(0.129)$ & $.0258(.158)$ \\
\hline Fog & $1.23(0.0510)$ & $0.0279(0.237)$ & $.0036(.0600)$ \\
\hline Dark & $0.646(0.132)$ & $0.356(0.0374)$ & $.182(.386)$ \\
\hline Weekday & $-.354(0.149)$ & $-0.154(0.0368)$ & $.790(.407)$ \\
\hline Negligent (v1) & $-1.83(0.230)$ & $-0.0122(0.0398)$ & $.267(.443)$ \\
\hline Negligent (v2) & $-1.17(0.208)$ & $0.177(0.0388)$ & $.251(.433)$ \\
\hline Negligent (v1\&v2) & $2.33(0.497)$ & $0.231(0.0850)$ & $.0382(.192)$ \\
\hline Age $<21(\mathrm{v} 1)$ & $-.121(0.174)$ & $-0.116(0.0424)$ & $.182(.386)$ \\
\hline Age $<21(\mathrm{v} 2)$ & $-.0442(0.209)$ & $0.0102(0.0460)$ & $.149(.355)$ \\
\hline Age $>60(\mathrm{v} 1)$ & $1.13(0.136)$ & $0.199(0.0453)$ & $.125(.332)$ \\
\hline Age $>60(\mathrm{v} 2)$ & $-0.665(0.257)$ & $0.134(0.0497)$ & $.103(.304)$ \\
\hline Divided hwy & $0.171(0.141)$ & $0.499(0.0343)$ & $.231(.421)$ \\
\hline Interstate hwy & $0.228(0.208)$ & $-0.370(0.0703)$ & $.043(.203)$ \\
\hline $\begin{array}{l}\text { Speed }>10 \mathrm{mph} \\
\text { above limit (v1) }\end{array}$ & $1.28(0.403)$ & $1.49(0.133)$ & $.00249(.573)$ \\
\hline $\begin{array}{l}\text { Speed }>10 \mathrm{mph} \\
\text { above limit (v2) }\end{array}$ & $1.72(0.490)$ & $1.27(.170)$ & $.00204(.520)$ \\
\hline $\begin{array}{l}\text { Number of } \\
\text { occupants (v1) }\end{array}$ & $0.294(0.0533)$ & $0.240(0.0145)$ & $1.47(.847)$ \\
\hline $\begin{array}{l}\text { Number of } \\
\text { occupants (v2) }\end{array}$ & $0.073(0.0480)$ & $0.0339(0.0150)$ & $1.44(.106)$ \\
\hline Intercept & $-6.21(0.259)$ & $-3.96(0.0652)$ & \\
\hline Year dummies? & Yes & Yes & \\
\hline $\mathrm{N}$ & 130,951 & 130,951 & \\
\hline $\log \mathrm{L}$ & -1383.8972 & -15005.193 & \\
\hline $\begin{array}{l}\text { Mean value of } \\
\text { dependent variable }\end{array}$ & $\begin{array}{l}.001596 \\
(.0399)\end{array}$ & $.02545(.157)$ & \\
\hline
\end{tabular}

Note: The dataset consists of all two-vehicle crashes involving at least one car. 
Table 2:

Predicted Change in Number of Crashes Involving Fatalities and Serious In juries per Year if Cars Replaced All Heavier Vehicles in the U.S.

Crashes Involving

Fatalities

Serious injuries

Change in the number of crashes per year involving car occupants if cars replace other types of vehicles, by type of vehicle:

$\begin{array}{lcc}\text { SUVs } & -202 & -1,008^{* *} \\ \text { Light trucks } & -1,445^{* *} & -11,325^{* *} \\ \text { Heavy trucks } & -561^{* *} & -3,384^{* *} \\ \text { Buses } & -51^{*} & -183\end{array}$

Change in the number of crashes per year involving SUV occupants if SUVs replace other types of vehicles, by type of vehicle:

$\begin{array}{lcc}\text { Cars } & +349 & +927 \\ \text { Light trucks } & -25 & -347 \\ \text { Heavy trucks } & -13 & -184^{* *} \\ \text { Buses } & -- & +17\end{array}$

Change in the number of crashes per year involving light truck occupants if light trucks replace other types of vehicles, by type of vehicle:

\begin{tabular}{lcc}
\hline Cars & $+864^{* *}$ & $+8,010^{* *}$ \\
SUVs & +4 & +65 \\
Heavy trucks & $-95^{* *}$ & $-722^{*}$ \\
Buses & -3 & -12
\end{tabular}

Change in the number of single-vehicle crashes per year if cars replaced other types of vehicles, by type of vehicle:

$\begin{array}{lcc}\text { SUV's } & -27^{*} & -- \\ \text { Light Trucks } & -58 & +485^{* *} \\ \text { Heavy Trucks } & -9 & -4 \\ \text { Buses } & -15^{* *} & --\end{array}$

Change in the number of crashes per year involving pedestrians/bicyclists if cars replaced other types of vehicles, by type of vehicle:

\begin{tabular}{lcc} 
SUV's & $-594^{* *}$ & +673 \\
Light Trucks & $-2,225^{* *}$ & $-4,633^{* *}$ \\
Heavy Trucks & $-486^{* *}$ & $-777^{*}$ \\
Buses & $-9 *$ & +143 \\
\hline
\end{tabular}

Note: Asterisks and double asterisks indicate statistical significance at the $90 \%$ level and 95\% level, respectively. 
Table 3: Results of Logit Regressions Explaining Fatalities and Injuries to Occupants of SUV's Involved in Two Vehicle Crashes

\begin{tabular}{|c|c|c|c|}
\hline & Fatalities & Serious injuries & Summary statistics \\
\hline $\mathrm{V} 2=\mathrm{car}$ & $-1.02(0.698)$ & $-0.189(0.256)$ & $.688(.463)$ \\
\hline $\mathrm{V} 2=$ light truck & $0.212(0.708)$ & $0.210(0.270)$ & $.232(.422)$ \\
\hline $\mathrm{V} 2=$ heavy truck & $0.927(0.904)$ & $0.928(0.315)$ & $.0279(.164)$ \\
\hline $\mathrm{V} 2=\mathrm{bus}$ & & $-0.568(1.14)$ & $.00442(.0663)$ \\
\hline Medium city & $-0.911(0.911)$ & $-0.604(0.174)$ & $.160(.368)$ \\
\hline Large city & $-0.673(0.463)$ & $-0.628(0.130)$ & $.305(.460)$ \\
\hline Used seatbelt (v1) & $-1.31(0.426)$ & $-0.334(0.114)$ & $.673(.469)$ \\
\hline Rain & $-0.0600(0552)$ & $-0.0651(0.190)$ & $.121(.326)$ \\
\hline Snow & $-2.241 .62)$ & $-1.22(0.471)$ & $.0265(.161)$ \\
\hline Fog & $2.48(1.02)$ & $0.259(0.737)$ & $.00434(.0657)$ \\
\hline Dark & $1.22(0.419)$ & $0.379(0.129)$ & $.180(.384)$ \\
\hline Weekday & $-0.223(0.448)$ & $-0.186(0.126)$ & $.784(.411)$ \\
\hline Negligent (v1) & $-3.85(0.753)$ & $-0.00273(0.146)$ & $.224(.417)$ \\
\hline Negligent (v2) & $-2.18(0.862)$ & $-0.0569(0.133)$ & $.280(.449)$ \\
\hline Negligent (v1\&v2) & $4.92(1.67)$ & $0.180(0.320)$ & $.0309(.173)$ \\
\hline Age $<21(\mathrm{v} 1)$ & $-0.296(0.658)$ & $-0.183(0.156)$ & $.151(.358)$ \\
\hline Age < 21 (v2) & $-0.264(0.636)$ & $0.295(0.145)$ & $.175(.380)$ \\
\hline Age $>60(\mathrm{v} 1)$ & $1.34(0.649)$ & $-0.148(0.265)$ & $.0510(.220)$ \\
\hline Age $>60$ (v2) & $0.247(0.586)$ & $0.337(0.179)$ & $.0910(.288)$ \\
\hline Divided hwy & $-0.173(0.526)$ & $0.326(0.121)$ & $.246(.431)$ \\
\hline Interstate hwy & $-0.477(0.670)$ & $-0.106(0.227)$ & $.0501(.218)$ \\
\hline $\begin{array}{l}\text { Speed }>10 \mathrm{mph} \\
\text { above limit (v1) }\end{array}$ & $3.23(1.40)$ & $1.09(.742)$ & $.00144(.0380)$ \\
\hline $\begin{array}{l}\text { Speed }>10 \mathrm{mph} \\
\text { above limit (v2) }\end{array}$ & $3.10(1.12)$ & $1.19(.647)$ & $.00197(.0443)$ \\
\hline $\begin{array}{l}\text { Number of } \\
\text { occupants (v1) }\end{array}$ & $0.460(0.137)$ & $0.192(0.0424)$ & $1.50(.925)$ \\
\hline $\begin{array}{l}\text { Number of } \\
\text { occupants (v2) }\end{array}$ & $-0.210(0.242)$ & $0.0647(0.0456)$ & $1.46(.942)$ \\
\hline Intercept & $-5.29(0.989)$ & $-4.05(.338)$ & \\
\hline Year dummies? & Yes & Yes & \\
\hline $\mathrm{N}$ & 15,322 & 15,380 & \\
\hline $\log \mathrm{L}$ & -105.67893 & -1204.3696 & \\
\hline $\begin{array}{l}\text { Mean value of } \\
\text { dependent variable }\end{array}$ & $.00111(.0333)$ & $.0157(.125)$ & \\
\hline
\end{tabular}

Note: The dataset is all two-vehicle crashes involving at least one SUV. Blanks in column 1 indicate a variable for which no coefficient could be computed. 
Table 4: Results of Logit Regressions Explaining Fatalities and Injuries to Occupants of Light Trucks Involved in Two Vehicle Crashes

\begin{tabular}{|c|c|c|c|}
\hline & Fatalities & Serious injuries & Summary statistics \\
\hline $\mathrm{V} 2=\mathrm{car}$ & $-0.714(0.309)$ & $-0.376(0.0752)$ & $.740(.438)$ \\
\hline $\mathrm{V} 2=\mathrm{SUV}$ & $-0.0361(0.467)$ & $-0.0352(0.123)$ & $.0639(.244)$ \\
\hline $\mathrm{V} 2=$ heavy truck & $1.69(0.333)$ & $0.727(0.110)$ & $.0345(.183)$ \\
\hline $\mathrm{V} 2=$ bus & $0.431(1.11)$ & $0.0861(0.369)$ & $.00490(.0698)$ \\
\hline Medium city & $-0.619(0.398)$ & $-0.269(0.0887)$ & $.127(.333)$ \\
\hline Large city & $-1.61(0.344)$ & $-0.647(0.0727)$ & $.264(.441)$ \\
\hline Used seatbelt (v1) & $-1.53(0.226)$ & $-0.454(0.0593)$ & $.724(.447)$ \\
\hline Rain & $-0.311(.370)$ & $\begin{array}{l}-0.00219 \\
(0.0927)\end{array}$ & $.120(.325)$ \\
\hline Snow & $-0.888(0.599)$ & $-0.805(0.250)$ & $.0274(.163)$ \\
\hline Fog & & $-0.201(0.440)$ & $.00341(.0583)$ \\
\hline Dark & $1.10(.243)$ & $0.439(0.0685)$ & $.157(.364)$ \\
\hline Weekday & $-0.510(0.241)$ & $-.250(0.0668)$ & $.807(.394)$ \\
\hline Negligent (v1) & $-1.90(0.504)$ & $-0.165(0.0737)$ & $.265(.441)$ \\
\hline Negligent (v2) & $-1.19(0.348)$ & $0.0485(0.0693)$ & $.277(.448)$ \\
\hline Negligent (v1\&v2) & $1.16(1.17)$ & $0.554(0.151)$ & $.0389(.193)$ \\
\hline Age $<21(\mathrm{v} 1)$ & $0.0743(0.383)$ & $0.0116(0.0901)$ & $.122(.327)$ \\
\hline Age $<21(\mathrm{v} 2)$ & $-0.0546(0.344)$ & $0.0113(0.0801)$ & $.172(.378)$ \\
\hline Age $>60(\mathrm{v} 1)$ & $1.25(0.254)$ & $0.176(0.0914)$ & $.088(.283)$ \\
\hline Age $>60(\mathrm{v} 2)$ & $-0.268(0.448)$ & $0.110(0.0924)$ & $.115(.319)$ \\
\hline Divided hwy & $-0.151(0.268)$ & $0.308(0.0639)$ & $.235(.424)$ \\
\hline Interstate hwy & $0.443(0.367)$ & $-.463(0.130)$ & $.0474(.212)$ \\
\hline $\begin{array}{l}\text { Speed > } 10 \mathrm{mph} \\
\text { above limit (v1) }\end{array}$ & $2.14(.794)$ & $1.58(0.281)$ & $.00228(.0476)$ \\
\hline $\begin{array}{l}\text { Speed }>10 \mathrm{mph} \\
\text { above limit (v2) }\end{array}$ & $.908(1.23)$ & $1.26(0.281)$ & $.00267(.0516)$ \\
\hline $\begin{array}{l}\text { Number of } \\
\text { occupants (v1) }\end{array}$ & $0.105(0.0708)$ & $0.241(0.0192)$ & $1.44(.915)$ \\
\hline $\begin{array}{l}\text { Number of } \\
\text { occupants (v2) }\end{array}$ & $0.155(0.0558)$ & $0.0127(0.0333)$ & $1.46(.883)$ \\
\hline Intercept & $-5.67(0.483)$ & $-3.68(0.128)$ & \\
\hline Year dummies? & Yes & Yes & \\
\hline $\mathrm{N}$ & 56,401 & 56,642 & \\
\hline $\log \mathrm{L}$ & -357.138 & -4732.5836 & \\
\hline $\begin{array}{l}\text { Mean value of } \\
\text { dependent variable }\end{array}$ & $.000966(.0311)$ & $.01727(.1303)$ & \\
\hline
\end{tabular}

Notes: The dataset consists of all two-vehicle crashes involving at least one light truck. A blank in columns 1 indicates a variable for which no coefficient could be computed. 
Table 5: Results of Logit Regressions Explaining Fatalities and Serious Injuries to Occupants of Vehicles Involved in Single Vehicle Crashes

\begin{tabular}{|l|l|l|l|}
\hline & Fatalities & Serious injuries & Mean (s.d.) \\
\hline SUV & $1.93(1.12)$ & & $0.0519(.222)$ \\
\hline Light truck & $1.02(0.750)$ & $-0.975(0.487)$ & $0.209(.407)$ \\
\hline Heavy truck & $1.25(2.25)$ & $0.0663(0.657)$ & $0.0274(.163)$ \\
\hline Bus & $3.92(1.58)$ & & $0.0137(.116)$ \\
\hline Medium city & $0.330(0.868)$ & $-0.489(0.507)$ & $0.104(.305)$ \\
\hline Large city & $-2.16(0.996)$ & $-1.16(0.376)$ & $0.391(.488)$ \\
\hline Used seatbelt & $-2.09(0.824)$ & $-.535(0.337)$ & $.617(.485)$ \\
\hline Rain & $1.27(0.899)$ & $0.0725(0.506)$ & $.0852(.279)$ \\
\hline Snow & & $0.0784(0.995)$ & $.0108(.103)$ \\
\hline Fog & & & $.00293(.0540)$ \\
\hline Dark & $0.202(0.617)$ & $0.894(0.336)$ & $.227(.418)$ \\
\hline Weekday & $-0.507(0.738)$ & $0.228(0.380)$ & $.765(.423)$ \\
\hline Negligent & $1.23(.686)$ & $-.183(.552)$ & $.0864(.281)$ \\
\hline Age $<21$ & & $0.0612(0.393)$ & $.139(.345)$ \\
\hline Age $>60$ & $2.33(0.682)$ & $-0.627(0.622)$ & $.130(.336)$ \\
\hline Divided hwy & $3.22(0.827)$ & $1.01(0.364)$ & $.129(.334)$ \\
\hline Interstate hwy & $3.12(1.20)$ & $0.997(0.747)$ & $.0160(.126)$ \\
\hline $\begin{array}{l}\text { Speed }>10 \text { mph } \\
\text { above limit }\end{array}$ & & $1.87(0.854)$ & $.00894(.0941)$ \\
\hline $\begin{array}{l}\text { Number of } \\
\text { occupants }\end{array}$ & $.0920(0.101)$ & $0.141(0.0878)$ & $1.36(0.863)$ \\
\hline Intercept & $-9.62(1.04)$ & $-5.04(0.488)$ & \\
\hline Year dummies? & Yes & Yes & \\
\hline $\mathrm{N}$ & 11,047 & 12,148 & \\
\hline Log L & -33.41 & -383.48 & \\
\hline $\begin{array}{l}\text { Mean value of } \\
\text { dependent variable }\end{array}$ & $.000618(.0248)$ & $.00533(.0728)$ & \\
\hline
\end{tabular}

Note: The dataset consists of all single-vehicle crashes. Blanks in columns 1 and 2 indicate variables for which coefficients could not be computed. 
Table 6:

Results of Logit Regressions Explaining Fatalities and Serious Injuries to Pedestrians or Cyclists Hit by Vehicles

\begin{tabular}{|l|l|l|l|}
\hline & Fatalities & Serious injuries & Mean (s.d.) \\
\hline SUV & $0.680(0.247)$ & $-0.106(0.130)$ & $0.0536(.225)$ \\
\hline Light truck & $0.679(0.158)$ & $0.192(0.0697)$ & $0.200(.400)$ \\
\hline Heavy truck & $1.51(0.316)$ & $0.407(0.220)$ & $0.0157(.124)$ \\
\hline Bus & $0.0715(0.815)$ & $-0.150(0.290)$ & $0.0081(.0910)$ \\
\hline Medium city & $-0.502(0.246)$ & $-0.109(0.0930)$ & $0.105(.309)$ \\
\hline Large city & $-0.874(0.154)$ & $-0.370(0.057)$ & $0.408(.491)$ \\
\hline Rain & $-0.626(0.266)$ & $0.00157(0.0993)$ & $0.0796(.271)$ \\
\hline Snow & $-1.10(0.660)$ & $-0.482(0.296)$ & $0.00715(.0842)$ \\
\hline Fog & $1.58(0.640)$ & $0.0832(0.397)$ & $0.00311(.0556)$ \\
\hline Dark & $1.71(0.141)$ & $0.418(0.0620)$ & $0.245(.429)$ \\
\hline Weekday & $-0.241(0.149)$ & $-0.106(0.0642)$ & $0.765(2.97)$ \\
\hline Negligent (vehicle) & $-0.350(0.156)$ & $0.00261(0.0623)$ & $0.320(.466)$ \\
\hline $\begin{array}{l}\text { Age }<21 \\
\text { (ped./cyclist) }\end{array}$ & $-0.338(0.169)$ & $-0.169(0.0594)$ & $0.487(.500)$ \\
\hline Age $<21$ (vehicle) & $0.356(0.194)$ & $0.0942(0.0792)$ & $0.137(.344)$ \\
\hline $\begin{array}{l}\text { Age }>60 \\
\text { (ped./cyclist) }\end{array}$ & $1.46(0.177)$ & $0.442(0.0985)$ & $0.0750(.263)$ \\
\hline Age $>60$ (vehicle) & $-0.247(0.258)$ & $-0.0777(0.0863)$ & $0.126(.332)$ \\
\hline Divided hwy & $1.01(0.155)$ & $0.424(0.0748)$ & $0.126(.331)$ \\
\hline Interstate hwy & $1.54(0.361)$ & $0.598(0.307)$ & $0.00507(0.0722)$ \\
\hline $\begin{array}{l}\text { Speed }>10 \text { mph } \\
\text { above limit (veh.) }\end{array}$ & $1.35(0.408)$ & $1.13(0.308)$ & $0.00818(.0901)$ \\
\hline $\begin{array}{l}\text { Number of } \\
\text { occupants (veh.) }\end{array}$ & $0.0444(0.0738)$ & $0.0831(0.0285)$ & $1.34(.901)$ \\
\hline Intercept & $-4.74(0.274)$ & $-1.73(.115)$ & \\
\hline Year dummies? & Yes & Yes & \\
\hline $\mathrm{N}$ & 13,896 & 13,896 & -6601.2219 \\
\hline Log L & -1230.4994 & $.00111(.0333)$ & \\
\hline $\begin{array}{l}\text { Mean value of } \\
\text { dependent variable }\end{array}$ & $.000150(.0122)$ & & \\
\hline & & & \\
\hline
\end{tabular}

Note: The dataset consists of all crashes involving a vehicle hitting pedestrians or cyclists 


\section{Table 7:}

\section{The External and Internal Effects on Fatal Crashes of Replacing SUV's and Light Trucks with Cars}

\begin{tabular}{|c|c|c|}
\hline External effects & SUVs & Light Trucks \\
\hline $\begin{array}{c}\text { Decrease in number of two-vehicle crashes per year } \\
\text { involving deaths of car occupants if all SUVs or light } \\
\text { trucks were replaced by cars }\end{array}$ & -202 & $-1,445$ \\
\hline $\begin{array}{c}\text { Decrease in number of two-vehicle crashes per year } \\
\text { involving deaths of SUV occupants if all light trucks were } \\
\text { replaced by cars }\end{array}$ & -- & -25 \\
\hline $\begin{array}{c}\text { Decrease in number of crashes per year involving deaths } \\
\text { of pedestrians and bicyclists if all SUVs or light trucks } \\
\text { were replaced by cars }\end{array}$ & -594 & $-2,225$ \\
\hline Total & -796 & $-3,695$ \\
\hline Internal effects & -27 & -58 \\
\hline $\begin{array}{c}\text { Decrease in number of crashes per year involving deaths } \\
\text { of SUV or light truck occupants in single-vehicle crashes } \\
\text { if all SUV's or light trucks were replaced by cars }\end{array}$ & & \\
\hline $\begin{array}{c}\text { Increase in the number of two-vehicle crashes per year } \\
\text { involving deaths of SUV or light truck occupants if } \\
\text { all SUVs or light trucks were replaced by cars }\end{array}$ & $+1,846$ & $+1,493$ \\
\hline Total & $+1,819$ & $+1,435$ \\
\hline External plus Internal Effects & $+1,023$ & $-2,260$ \\
\hline Ratio of external effect to internal effect & 0.44 & 2.6 \\
\hline
\end{tabular}




\section{Table 8:}

\section{The External and Internal Effects of SUV's and Light Trucks in Crashes involving Serious Injuries}

\begin{tabular}{|c|c|c|}
\hline & SUV's & $\begin{array}{l}\text { Light } \\
\text { Trucks }\end{array}$ \\
\hline \multicolumn{3}{|l|}{ External effects } \\
\hline $\begin{array}{l}\text { Decrease in number of two-vehicle crashes per year } \\
\text { involving serious injuries of car occupants if all SUVs or } \\
\text { light trucks were replaced by cars: }\end{array}$ & $-1,008$ & $-11,325$ \\
\hline $\begin{array}{c}\text { Decrease in number of two-vehicle crashes per year } \\
\text { involving serious injuries of SUV occupants if all light } \\
\text { trucks were replaced by cars: }\end{array}$ & -- & -347 \\
\hline $\begin{array}{c}\text { Change in number of crashes per year involving serious } \\
\text { injuries of pedestrians and bicyclists if all SUVs or light } \\
\text { trucks were replaced by cars: }\end{array}$ & +673 & $-4,633$ \\
\hline Total & -335 & $-16,305$ \\
\hline \multicolumn{3}{|l|}{ Internal effects } \\
\hline $\begin{array}{l}\text { Decrease in number of crashes per year involving serious } \\
\text { injuries of SUV or light truck occupants in single-vehicle } \\
\text { crashes if all SUVs or light trucks were replaced by cars: }\end{array}$ & -- & +485 \\
\hline $\begin{array}{l}\text { Increase in the number of two-vehicle crashes per year } \\
\text { involving serious injuries of SUV or light truck occupants if } \\
\text { all SUVs or light trucks were replaced by cars: }\end{array}$ & $+39,482$ & $+24,284$ \\
\hline Total & $+39,482$ & $+24,769$ \\
\hline External plus Internal Effects & $+39,147$ & $+8,464$ \\
\hline Ratio of external effect to internal effect & .00085 & .66 \\
\hline
\end{tabular}




\section{Appendix: \\ Breakdown of Crashes by Vehicle Type}

\section{All Crashes}

\begin{tabular}{|l|c|}
\hline Two vehicle crashes & 0.719 \\
\hline Single vehicle crashes & 0.0655002 \\
\hline Crashes involving pedestrian or cyclist & 0.1227386 \\
\hline Crashes involving motorcycle & 0.0136546 \\
\hline Crashes involving more than two vehicles & 0.0786002 \\
\hline
\end{tabular}

Two Vehicle Crashes

\begin{tabular}{|l|c|c|c|c|c|}
\hline & Car & SUV & $\begin{array}{c}\text { Light } \\
\text { Truck }\end{array}$ & $\begin{array}{c}\text { Heavy } \\
\text { Truck }\end{array}$ & Bus \\
\hline Car & 0.399 & 0.0634 & 0.252 & 0.135 & 0.00586 \\
\hline SUV & 0.0634 & 0.00464 & 0.0211 & 0.00928 & 0.00037 \\
\hline Light Truck & 0.252 & 0.0211 & 0.0539 & 0.0388 & 0.00166 \\
\hline Heavy Truck & 0.135 & 0.00928 & 0.0388 & 0.0127 & 0.000898 \\
\hline Bus & 0.00586 & 0.00037 & 0.00166 & 0.000898 & 0.000249 \\
\hline
\end{tabular}

Single Vehicle Crashes

\begin{tabular}{|l|c|}
\hline Car & 0.698 \\
\hline SUV & 0.0519 \\
\hline Light truck & 0.209 \\
\hline Heavy truck & 0.0274 \\
\hline Bus & 0.0137 \\
\hline
\end{tabular}

\section{Crashes Involving Pedestrians/Bicyclists}

\begin{tabular}{|l|c|}
\hline Car & 0.722 \\
\hline SUV & 0.0530 \\
\hline Light truck & 0.201 \\
\hline Heavy truck & 0.0159 \\
\hline Bus & 0.0081 \\
\hline
\end{tabular}

Source: Calculated by the author from General Estimates System, National Highway Traffic Safety Administration. 


\section{References}

Coate, Douglas, and James VanderHoff (2001), "The Truth about Light Trucks," Regulation, Spring 2001.

Crandall, Robert W., and John D. Graham (1989), "The Effect of Fuel Economy Standards on Automobile Safety," J. of Law \& Economics, vol. XXXII, pp. 97-118.

Joksch, Hand, Dawn Massie, and Robert Pickier (1998), "Vehicle Aggressivity: Fleet Characterization Using Traffic Collision Data,” DOT HS 808679.

Keeler, Theodore E. (1994), "Highway Safety, Economic Behavior, and Driving Enforcement," American Economic Review 40:2, pp. 684-693.

Liao, Yu-ping, and Michelle J. White (2002), "No-Fault for Motor Vehicles: An Economic Analysis," American Law and Economics Review, vol. 4:2, pp. 258-294 (2002).

National Highway Traffic Safety Administration (1991), A Collection of Recent Analyses of Vehicle Weight and Safety (DOT HS-807 677, May 1991),

National Highway Traffic Safety Administration (1997), The Effect of Decrease in Vehicle Weight on Injury Crash Weights (DOT HS 808 575, January1997).

Peltzman, Sam (1975), "The Effects of Automobile Safety Regulation," J. of Political Economy, vol: 83:4, pp. 677-725.

Rist, Curtis (2001), "Roll Over, Newton: The Design of Sport Utility Vehicles is Enough to Make the Father of Physics Turn in His Grave," Discover, vol. 22:4, pp. 44-49, April.

Shavell, Steven (1987), Economic Analysis of Accident Law. Cambridge: Harvard University Press.

White, Michelle J. (1998), “Comparative versus Contributory Negligence: Empirical Comparisons," in The New Palgrave Dictionary of Economics and the Law, P. Newman, editor, London: Macmillan Press. 